\title{
ANALYSIS OF MOLECULAR AND MORPHOLOGICAL CHARACTERISTICS OF PLANTS TRANSFORMED WITH ANTIFUNGAL GENE
}

\author{
Aparna Islam ${ }^{1}$, Afif Hassairi and Vanga S. Reddy \\ Plant Transformation Group, International Centre for Genetic Engineering and Biotechnology, \\ ICGEB Campus, New Delhi-110067, India
}

Key words: Ca-AFP, Tobacco, Chickpea, Defensin peptide, Bacteriostatic antibiotics

\begin{abstract}
A defensin gene isolated from chickpea (Cicer arietinum L.), $C a-A F P$ in the background of pCAMBIA1301 was transferred into tobacco (Nicotiana tabaccum L. var. petit havana) genome following transformation using Agrobacterium tumefaciens strain LBA4404. Although all the explants showed GUS activity after co-cultivation, transgenic tobacco shoots were regenerated only from those explants cultured in presence of bacteriostatic antibiotic carbenicillin under hygromycin selection. Presence of the antifungal gene in the regenerated plants was confirmed by PCR, while integration of the whole T-DNA was demonstrated by southern blot hybridization. Furthermore, southern blot hybridization revealed that most of the transgenics contained single copy of the T-DNA while few were found to have multiple copies. Expression of the GUS and $C a-A F P$ genes in the transgenic plants was observed. Morphological analysis demonstrated that presence of the transgenes produced no morphological abnormality or yield discrepancy in the transgenics.
\end{abstract}

\section{Introduction}

Of various plant diseases, fungal diseases play the most damaging role in our agriculture. To protect plants from fungal pathogens and to improve crop production, many strategies are under practice (Grover and Gowthaman 2003). Broglie et al. (1991) was the first to produce plants with an antifungal gene to attain this goal and since then many genes have been introduced into plant genomes to enhance host resistance. For example, hydrolytic enzymes like chitinase and glucanase, PR-proteins like thionins and osmotins, phytoalxins, elicitors etc. (Grover and Gowthaman 2003).

Progress in achieving sustainable and effective fungus resistance through genetic engineering is, however, lagging behind in comparison to success in developing herbicide, insect pest and virus resistant transgenic plants (Punja 2001). Antifungal gene transformation and expression present many more challenges including hurdles involved with transformation techniques. Antifungal proteins which are mostly cationic (e.g. defensins, cercopins and megainins) are not only toxic to fungi but also have toxicity towards the host plants (Hancock and Lehrer 1998). A number of reports suggested that constitutive expression of these proteins and peptides might induce plant cell damage (Osusky et al. 2000) and cause deleterious effect on plant growth and development (Honée et al. 1995). To overcome these, pathogen-induced expression of antimicrobial gene in transgenics has been explored lately (Yevtushenko et al. 2005). Alternatively, attention has also been given to attain broad-spectrum resistance from small genes as they can be synthesized swiftly and with less effort by the plants. As a result, small synthetic peptide like MsrA1 (Osusky et al. 2000) and natural peptides like plant defensins (Gao et al. 2000) have been explored to enhance fungal disease resistance in transgenic plants.

In the present study we chose a plant defensin peptide, Ca-AFP (antifungal peptide from Cicer arietinum L.) to produce transgenics. This peptide was characterized to have broad antifungal activity ranging from chitin containing fungus Alternaria solani to Pythium aphanidermatum, which is devoid of chitin in their cell wall (Islam 2004). The peptide was found

\footnotetext{
${ }^{1}$ Corresponding author. This work is a part of the Ph.D. thesis of the first author. Department of Mathematics and Natural Sciences, BRAC University, 66, Mohakhali, Dhaka-1212, Bangladesh.

E-mail: aparnai20@yahoo.com
} 
to be encoded by a single gene of 225 bp (Gene Bank acc. No. DQ 288897) (Islam 2004). As tobacco is a model system to assess efficiency of any new gene, we introduced this defensin gene into tobacco genome and regenerated transgenics. Following molecular analysis of the transgenic nature we analyzed the effect of the transgene on growth and development of the transgenic plants. Finally, stable integration of the transgenes was also checked during this study.

\section{Materials and Methods}

Transformation vector construction: The coding sequence of Ca-AFP gene (225 bp) was PCR amplified (Islam 2004) from chickpea genomic DNA (template) using AFP5'MBam (5' - CGC GGA TCC atg gcg agg tgt gag aat ttg gct - 3') and AFPC2BS (5'- GCG GAT CCG AGC TCt taa caa ttt ttg gtg cac caa - 3') primers. The amplified PCR product was digested with BamHI and cloned into the same site of plasmid pFF19 (Marja et al. 1990) to yield plasmid pFF19-Ca-AFP. The $1.2 \mathrm{~Kb}$ fragment of $\mathrm{Ca}-\mathrm{AFP}$ cassette including CaMV35S enhancer, CaMV35S promoter, $\mathrm{Ca}$ $A F P$ and CaMV35S polyA was taken from the pFF19-Ca-AFP through EcoRI and HindIII digestion and cloned into Agrobacterium transformation vector pCAMBIA1301 between GUS and Hygromycin marker genes at EcoRI and HindIII sites of MCS of the vector. The final construct was designated as pICGEB-Ca-AFP (Fig. 1).

Tobacco transformation: Agrobacterium tumefaciens strain LBA4404 harboring pICGEB-CaAFP or empty vector pCAMBIA1301 alone was used to transform tobacco by leaf disc method (Horsch et al. 1985). Following two days of co-cultivation both the batches of leaf discs along with untransformed tobacco leaf discs were cultured on MS medium supplemented with hygromycin $(30 \mathrm{mg} / \mathrm{l})$ and bacteriostatic antibiotics either carbenicillin $(500 \mathrm{mg} / \mathrm{l})$ or cefotaxime $(500 \mathrm{mg} / \mathrm{l})$. A set of un-transformed leaf discs was also cultured as control in regeneration medium without selection.

GUS histo-chemical assay: For the detection of GUS expression in regenerated shoots GUS histo-chemical assay was performed as per the protocol developed by Jefferson (1987) and visualized under a microscope.

Molecular analysis: Molecular analysis of the regenerated plantlets was performed to determine their transgenic nature at DNA and protein levels.

Southern blot analysis: Genomic DNA of young leaves from regenerated transformed and untransformed control plants was isolated according to Michiels et al. (2003). PCR was performed using $C a-A F P$ specific primers AFP5'MBam and AFPC2BS, and GUS gene specific primers GUS5' primer (5' - cgc gga tcc atc tta gct cet gta gaa aac ccc) and GUS3' primer (5' - gct cga gct ccc ggg tca ttg gcc tcc ctg ctg). Expected products of $C a-A F P$ and $G U S$ gene specific primers are $225 \mathrm{bp}$ and $1.8 \mathrm{~Kb}$, respectively. The integration of the T-DNA and insertion pattern was determined through Southern blot hybridization. Genomic DNA was restricted with EcoRI and HindIII and probed with $C a-A F P$ gene sequence to detect the $1.2 \mathrm{~Kb}$ integrated gene fragment. If the expected $1.2 \mathrm{~Kb}$ is observed then it would indicate that the whole T-DNA has incorporated into the host plant genome as the location of Ca-AFP cassette is in between GUS and Hygromycin gene. For the determination of number of independent insertion of the transgenes, the genomic DNA was restricted with HindIII which cut the T-DNA at a unique site between GUS and $\mathrm{Ca}-A F P$ cassette. When the digested product is probed either with the $G U S$ or $C a-A F P$ gene sequence it would detect all the copies of GUS and $C a-A F P$ genes.

Dot blot experiment: To determine the antifungal gene expression total protein from the transgenic and control plants was tested through dot blot experiment. Following loading of crude protein samples detection was done according to Towbin et al. (1979).

Morphological analysis: Following confirmation of the transgenic nature, morphological characters such as plant height, number of leaf and leaf area were calculated two month s after they 
were transferred to greenhouse. Though plants started flowering after three months, flower number was recorded after four months. Pods were collected on maturity and average of five pods was calculated. All the data were collected from five individuals of each transgenic plant line.

\section{Results and Discussion}

Transgenic plant production: Only the infected leaf discs (either pICGEB-Ca-AFP or pCAMBIA1301) that were cultured in presence of carbenicillin survived and regenerated shoots within three - four weeks (Fig. 2a). The regenerated shoots were then transferred to fresh MS basal medium supplemented with hygromycin for further growth and root formation. More than $94 \%$ of the shoots rooted and also showed positive reaction during GUS histochemical activity test. The rooted plantlets successfully acclimatized in greenhouse and matured to flower in three months like the control plants and fruits were collected on maturity.

On the other hand, the survival and regeneration frequency was extremely low in pCAMBIACa-AFP infected leaf discs cultured in cefotaxime supplemented media (Fig. 2b). Here the regenerated shoots were found to attain a maximum height of $1 \mathrm{~cm}$ but they died in subsequent subculture. The untransformed leaf discs (control) did not survive on the selection medium (Fig. 2c).

Yu et al. (2001) showed that bacteriostatic antibiotics, cefotaxime and carbenicillin are not only antibacterial but also affect regeneration process. Silva and Fukai (2001) reported that the success in transgenic plant regeneration relies on the fine balance of four points, such as (1) the plant, (2) the Agrobacterium, (3) selection agent and (4) the agent for eliminating Agrobacterium. They reported enhanced shoot regeneration in presence of cefotaxime while reduced regeneration in presence of carbenicillin in tobacco under kanamycin selection following Agrobacteium strain LBA4404 infection. Using the same plant species and bacterial strain our observation contradicts this report when we tried to regenerate transgenic tobacco under hygromycin selection. We found no regeneration in presence of cefotaxime. Negative effect of cefotaxime was reported in various plants including tomato (Ling et al. 1998) and chrysanthemum (Silva and Fukai 2001), while negative impact of both carbenicillin and cefotaxime on regeneration was observed in rose by $\mathrm{Li}$ et al. (2002).

Molecular analysis of regenerated plants: PCR performed with Ca-AFP and GUS gene specific primers amplified the expected $225 \mathrm{bp}$ and $1.8 \mathrm{~Kb}$ long DNA fragment, respectively. This confirmed the presence of these two transgenes within the in vitro grown plant genome regenerated in presence of hygromycin selection (Fig. 3a-b). GUS positive reaction of these hygromycin resistant transgenic plants during histochemical assay indicates insertion of the whole GUS and Hygromycin cassettes, and expression of these two foreign genes. When PCR positive plants were further analyzed through Southern blot hybridization using $C a-A F P$ probe, a $1.2 \mathrm{~Kb}$ band representing the whole $C a-A F P$ cassette was found in all the regenerated plants (Fig. 4a). All these data demonstrated that during integration of the T-DNA into the host genome rearrangements, deletion or incomplete integration had not occurred.

Most of the transgenic plants showed the presence of one to three copies of inserted T-DNA in respect to transgenes $G U S$ (Fig. 4b) and Ca-AFP. Lorito et al. (1998) also reported one to three copies of insertion of antifungal endochitinase gene in tobacco through Agrobacterium-mediated transformation. Multiple copy insertion is often reported in transgenic tobacco transformed through same method (Finnegan and McElroy 1994).

All the hygromycin resistant transgenic plants that were found positive for the GUS gene at molecular level were also found positive at protein level when histochemical assay was performed. When dot blot experiments of the crude protein samples were performed with $C a-A F P$ antibody, expression of the $C a-A F P$ gene at protein level was also observed in all of these plants (data not shown). These data demonstrated that all the transgenes expressed in the transgenic plants. 

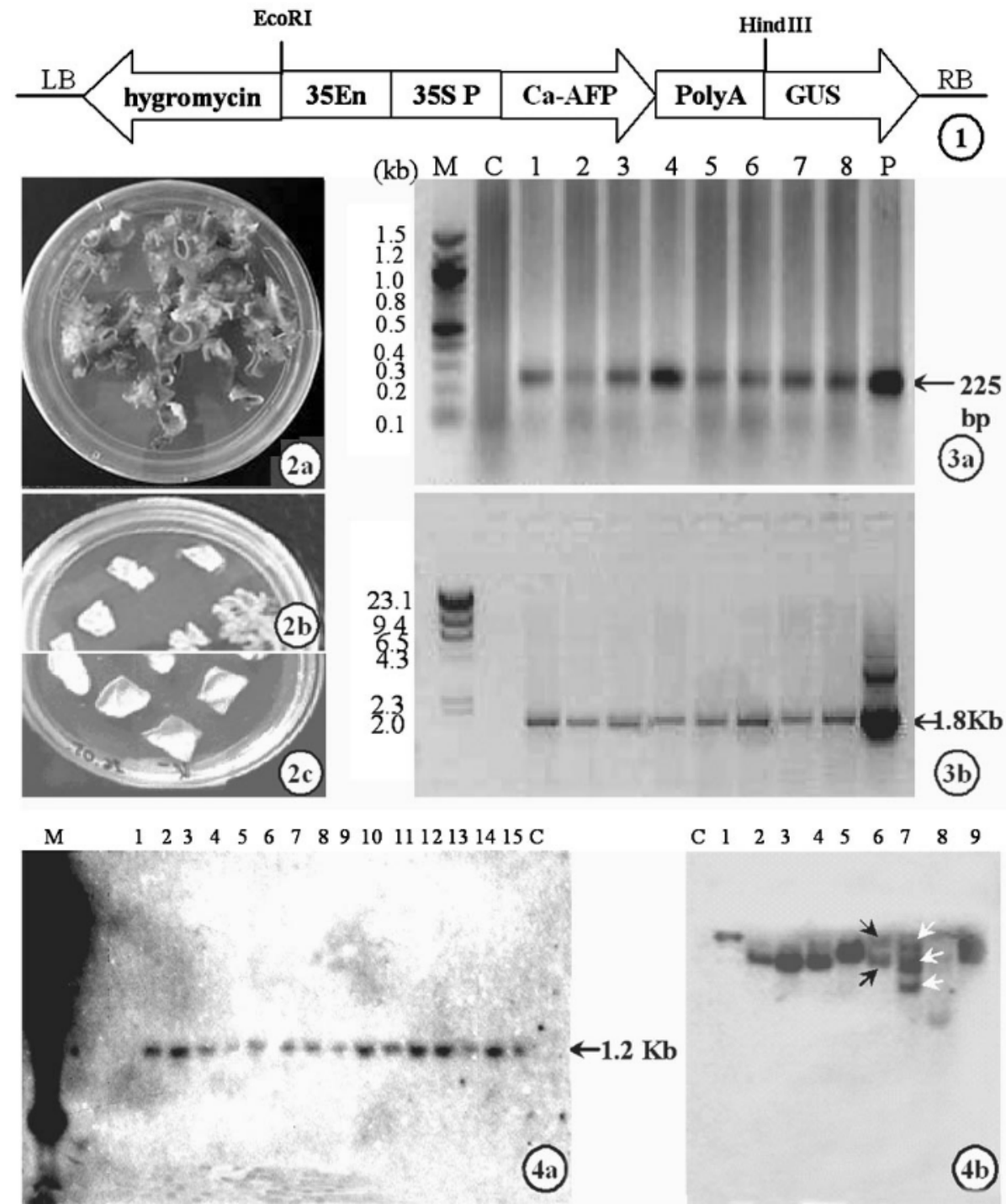

C $\begin{array}{lllllllll}1 & 2 & 3 & 4 & 5 & 6 & 7 & 8 & 9\end{array}$

Fig. 1. Map of the binary vector pICGEB-Ca-APP: antifungal gene. GUS and hygromycine: marker genes, $35 \mathrm{~S}$ En, 35S P and PolyA: CaMV 35S enhancer, promoter and polyA signal. 2. Regeneration from infected tobacco leaf discs in presence, a: carbenicillin, b: cefotaxime, $\mathrm{c}$ : un-infected leaf discs under selection. 3. PCR confirmations of regenerated plants using a: $C a-A F P$ and b: GUS primers. 4. Southern blot analysis of transgenic plants. Genomic DNA, a: probed with $C a-A F P$. M: HindIII digested ë-DNA marker, Lane1-15: independent transgenic lines, C: un-transformed control. b: probed with GUS. Lane 1-9: independent transgenic lines, C: un-transformed control. Note that lane 6 and 7 have 2 and 3 copies of insert.

Morphological analysis of the transgenic plants: All the transgenic plants were found morphologically similar to the untransformed control plants (Table 1). Yield of both transformed and untransformed plants were also comparable. This indicates that introduction of this antifungal peptide under constitutive promoter along with an enhancer exerted no deleterious effect on the host morphology or yield. 
There are many reports of abnormal morphology in transgenics when attempts were made to produce fungus resistant transgenic plants. Osusky et al. (2000) reported lesion-mimicked phenotype in transgenic potato when they transformed cationic peptide to obtain broad-spectrum fungus resistance. Under constitutive promoter, transgenic tomato, was also reported to die when transformed with elicitor gene to produce fungus resistant plants (Honée et al. 1995).

Table 1. Comparison of morphological features of untransformed control plant with trangenic plants of six different lines.

\begin{tabular}{cccccc}
\hline $\begin{array}{c}\text { Plant } \\
\text { lines }\end{array}$ & $\begin{array}{c}\text { Plant height } \\
(\mathrm{cm})\end{array}$ & $\begin{array}{c}\text { No. of grown } \\
\text { up leaves }\end{array}$ & $\begin{array}{c}\text { Leaf area } \\
\left(\mathrm{cm}^{2}\right)\end{array}$ & $\begin{array}{c}\text { No. of flowers } \\
(\text { after 4 months })\end{array}$ & $\begin{array}{c}\text { Pod weight* } \\
(\mathrm{g})\end{array}$ \\
\hline $\begin{array}{c}\text { Untransformed } \\
\text { control }\end{array}$ & 95 & 22 & 156 & 20 & 0.81 \\
16 & 89 & 22 & 149 & 18 & 0.82 \\
56 & 88 & 23 & 151 & 18 & 0.78 \\
73 & 89 & 21 & 150 & 19 & 0.61 \\
102 & 96 & 23 & 157 & 21 & 0.68 \\
107 & 95 & 24 & 157 & 20 & 0.80 \\
111 & 94 & 24 & 154 & 22 & 0.95 \\
\hline
\end{tabular}

* Average of five pods is mentioned here.

\section{Acknowledgements}

The authors acknowledge the Pre-doctoral Fellowship from the International Centre for Genetic Engineering and Biotechnology (ICGEB) awarded to the first author (AI). They also thank H. T. Nguyen for pICGEB-Ca-AFP construct and Professor Zeba I. Seraj, Department of Biochemistry and Molecular Biology, University of Dhaka, for her valuable comments on a draft of the manuscript.

\section{References}

Broglie, K., I. Chet, M. Holliday, R. Cressman, P. Biddle, S. Knowlton, C.J. Mauvais and R. Broglie. 1991. Transgenic plants with enhanced resistance to the fungal pathogen Rhizoctonia solani. Sci. 254: 11941197.

Finnegan, J. and D. McElroy. 1994. Transgene activation: Plants fight back! Bio/Technology 12: 883-888.

Gao, A.G., S.M. Hakimi, C.A. Mittanck, Y. Wu, B.M. Woerner, D.M. Stark, D.M. Shah, J. Liang and C.M.T. Rommens. 2000. Fungal pathogen protection in potato by expression of a plant defensin peptide. Nat. Biotech. 18: 1307-1310.

Grover, A. and R. Gawthaman. 2003. Strategies for development of fungus-resistant transgenic plants. Curr. Sci. 84: 330-340.

Hancock, R.E.W. and R. Lehrer. 1998. Cationic peptides : A new source of antibiotics. Trends in Biotechnology 16: 82-88.

Honée, G., L.S. Melchers, V.G.A.A. Vleeshouwers, J.S.C. Van Roekel and J.G.M.D. Wit. 1995. Production of the AVR9 elicitor from the fungal pathogen Cladosporium fulvum in transgenic tobacco and tomato plants. Plant Mol. Biol. 29: 909-920.

Horsch, R.B., J.E. Fry, N.L. Hoffmann, D. Elchholtz, S.G. Rogers and R.T. Fraley. 1985. A simple and general method for transferring gene into plants. Sci. 227: 1129-1231.

Islam, A. 2004. Role of a small cysteine-rich antifungal protein isolated from chickpea in host defense mechanism. Ph.D. Thesis, International Centre for Genetic Engineering and Biotechnology (ICGEB), Jawaharlal Nehru University, pp. 129.

Jefferson, R.A. 1987. Assaying chimeric genes in plants: the GUS fusion system. Plant Mol. Biol. Rep. 5: 87405. 
Li, X., S.F. Krasnyanski and S.S. Korban. 2002. Optimization of the uidA gene transfer into somatic embryos of rose via Agrobacterium tumefaciens. Plant Physiol. Biochem. 40: 453-459.

Ling, H.Q., D. Kriseleit and M.W. Ganal. 1998. Effect of ticarcilline/potassium clavulanate on callus growth and shoot regeneration in Agrobacterium-mediated transformation of tomato (Lycopersicon exculentum Mill.). Plant Cell Rep. 17: 843-847.

Lorito, M., S.L. Woo, I.G. Fernandez, G. Colucci, G.E. Harman, J.A. Pintor-Toro, E. Filippone, S. Muccifora, C.B. Lawerence, A. Zoina, S. Tuzun and F. Scala. 1998. Gene from mycoparasitic fungi as a source for improving plant resistance to fungal pathogens. Proc. Natl. Acad. Sci. USA 95: 7860-7865.

Marja, C.P.T., P. Maliga, J. Vieira and J. Messing. 1990. The pFF plasmids: cassettes utilizing CaMV sequences for expression of foreign genes in plants. J. Biotech. 14: 333-344.

Michiels, A., W. Van den Ende, M. Tucker, L. Van Riet and A. Van Laere. 2003. Extraction of high-quality genomic DNA from latex-containing plants. Anal. Biochem. 315: 85-89.

Osusky, M., G. Zhou, L. Osuska, R.E. Hancock, W.W. Kay and S. Misra. 2000. Transgenic plants expressing cationic peptide chimeras exhibit broad-spectrum resistance to phytopathogens. Nat. Biotech. 18: 11621166.

Punja, Z.K. 2001. Genetic engineering of plants to enhance resistance to fungal pathogens - a review of progress and future prospects. Can. J. Plant Pathol. 23: 216-235.

Silva, J.A.T. and S. Fukai. 2001. The impact of carbenicillin, cefotaxime and vancomycin on chrysanthemum and tobacco TCL morphogenesis and Agrobacterium growth. J. Appl. Hort. 3: 3-12.

Towbin, H., T. Staehelin and J. Gordon. 1979. Electrophoretic transfer of proteins from polyacrylamide gels to nitrocellulose sheets: procedure and some applications. Proc. Natl. Acad. Sci. USA 76(9): 4350-4354.

Yevtushenko, D.P., R. Romero, B.S. Forward, R.E. Hancock, W.W. Kay and S. Misra. 2005. Pathogeninduced expression of a cecropin A-melittin antimicrobial peptide gene confers antifungal resistance in transgenic tobacco. J. Exp. Bot. 56: 1685-1695.

Yu, T.A., S.D. Yeh and J.S. Yang. 2001. Effects of carbenicillin and cefotaxime on callus growth and somatic embryogenesis from adventitious roots of papaya. Bot. Bull. Acad. Sin. 42: 281-286.

(Manuscript received on 23 September, 2006; revised on 8 April, 2007) 